\title{
A Multiomics Approach to Heterogeneity in Alzheimer's Disease: Focused Review and Roadmap
}

AmanPreet Badhwar, PhD ${ }^{\mathrm{a}, \mathrm{b}}$, G. Peggy McFall, $\mathrm{PhD}^{\mathrm{c}}$, Shraddha Sapkota, PhD ${ }^{\mathrm{e}}$, Sandra E. Black, MD ${ }^{\mathrm{e}, \mathrm{f}}$, Howard Chertkow, $\mathrm{MD}^{\mathrm{g}}$, Simon Duchesne, $\mathrm{PhD}^{\mathrm{h}, \mathrm{i}}$, Mario Masellis, MD, $\mathrm{PhD}^{\mathrm{f}}$, Liang Li, PhD ${ }^{j}$, Roger A. Dixon, $\mathrm{PhD}^{\mathrm{c}, \mathrm{d} *}$, Pierre Bellec, $\mathrm{PhD}^{\mathrm{a}, \mathrm{b} *}$

${ }^{a}$ Centre de Recherche de l'Institut Universitaire de Gériatrie de Montréal, Canada; 'Université de Montréal, Canada; ' Department of Psychology, University of Alberta, Canada; ${ }^{\mathrm{d}}$ Neuroscience and Mental Health Institute, University of Alberta, Canada; ${ }^{\mathrm{e}}$ Hurvitz Brain Sciences Research Program, Sunnybrook Research Institute, University of Toronto, Canada; fDepartment of Medicine (Neurology), Sunnybrook Health Sciences Centre, University of Toronto, Canada; 'Baycrest Health Sciences and the Rotman Research Institute, University of Toronto, hCentre CERVO, Quebec City Mental Health Institute, Quebec, Canada, iDepartment of Radiology, Faculty of Medicine, Université Laval, Canada; ${ }^{j}$ Department of Chemistry, University of Alberta, Canada * equal contribution

\section{Corresponding Author}

Dr. AmanPreet Badhwar

Centre de Recherche, Institut Universitaire de Gériatrie de Montréal

Université de Montréal

Montréal, QC, Canada H3W 1W5

Tel: 514-340-3540 ext. 3367

Fax: 514-340-2802

Email: amanpreet.badhwar@criugm.qc.ca

Short running title: Multiomics heterogeneity in Alzheimer's 
medRxiv preprint doi: https://doi.org/10.1101/19008615; this version posted October 10, 2019. The copyright holder for this preprint (which was not certified by peer review) is the author/funder, who has granted medRxiv a license to display the preprint in perpetuity. Author Submitted Versismade available under a CC-BY-NC-ND 4.0 International license. Badhwar et al.

\begin{abstract}
Etiological and clinical heterogeneity is increasingly recognized as a common characteristic of Alzheimer's disease and related dementias. This heterogeneity complicates diagnosis, treatment, and the design and testing of new drugs. An important line of research is discovery of multimodal biomarkers that will facilitate the targeting of subpopulations with homogeneous pathophysiological signatures. High-throughput 'omics' are unbiased data driven techniques that probe the complex etiology of Alzheimer's disease from multiple levels (e.g. network, cellular, and molecular) and thereby account for pathophysiological heterogeneity in clinical populations. This review focuses on data reduction analyses that identify complementary disease-relevant perturbations for three omics techniques: neuroimaging-based subtypes, metabolomics-derived metabolite panels, and genomics-related polygenic risk scores. Neuroimaging can track accrued neurodegeneration and other sources of network impairments, metabolomics provides a global small-molecule snapshot that is sensitive to ongoing pathological processes, and genomics characterizes relatively invariant genetic risk factors representing key pathways associated with Alzheimer's disease. Following this focused review, we present a roadmap for assembling these multiomics measurements into a diagnostic tool highly predictive of individual clinical trajectories, to further the goal of personalized medicine in Alzheimer's disease.
\end{abstract}

\title{
Keywords
}

Alzheimer's disease, multiomics biomarkers, neuroimaging subtype, metabolite panel, polygenic risk score

\section{Abbreviations}

$\mathrm{A} \beta$ or $\mathrm{A} \beta 42$ amyloid beta or amyloid beta 42

APOE apolipoprotein E

ADNI Alzheimer's Disease Neuroimaging Initiative

$\mathrm{CN}$ cognitively normal

FDG fluorodeoxyglucose

fMRI functional MRI

GWAS genome-wide association studies

lvPPA logopenic progressive aphasia

MAF minor allele frequency

MCI mild cognitive impairment

NDDs neurodegenerative diseases

NGS next-generation genome sequencing

PCA posterior cortical atrophy

PET positron emission tomography

PRS polygenic risk score

SNPs single nucleotide polymorphisms 
medRxiv preprint doi: https://doi.org/10.1101/19008615; this version posted October 10, 2019. The copyright holder for this preprint (which was not certified by peer review) is the author/funder, who has granted medRxiv a license to display the preprint in perpetuity. Author Submitted Versismade available under a CC-BY-NC-ND 4.0 International license . Badhwar et al.

\section{Introduction}

Alzheimer's disease is a complex, multifactorial pathology that manifests itself along a continuum of conditions, ranging from asymptomatic, to mild cognitive impairment (MCI), to dementia (specifically Alzheimer's disease dementia). Trials of disease-modifying therapies remain unsuccessful, and these persistent failures have been attributed to (1) intervention late in the disease process (i.e. symptomatic stage), by which time extensive irreversible damage has accrued, and (2) lack of precision intervention targets in a multifactorial condition. Accordingly, an important line of current research is directed at the discovery of multimodal biomarkers that will help facilitate the detection of Alzheimer's disease in asymptomatic populations, and the adaptation of intervention regimens to different target subpopulations in prevention trials (Anstey et al., 2015; Olanrewaju et al., 2015). This work reviews recent datadriven approaches to biomarker discovery, in three omics fields that capture complementary aspects of neurodegeneration and Alzheimer's disease risk factors. We further propose a roadmap for integrating these multiomics biomarkers to advance our understanding of heterogeneity in Alzheimer's disease, and promote efficacy in intervention trials.

Established Alzheimer's disease biomarkers currently capture three facets of the disease pathophysiology: amyloidosis, tauopathy, and specific aspects of neurodegeneration (Jack et $a l ., 2018)$. Although these biomarkers have been usefully applied to the crucial goal of early Alzheimer's disease detection (Sperling et al., 2011), they fall short in explaining the heterogeneity of individual clinical trajectories, and their ability to predict differential cognitive decline is modest (Dumurgier et al., 2017). Predicting progression to dementia is challenging, as patients diagnosed with probable Alzheimer's disease dementia show considerable heterogeneity in the cognitive domains impaired (Scheltens et al., 2016), and the presence or severity of established Alzheimer's disease biomarkers. For example, amyloidosis-andtauopathy-defined 'pure Alzheimer's disease neuropathology' is observed in only 30-50 percent of patients with probable Alzheimer's disease dementia (Beach et al., 2012; Robinson et al., 2018). The remaining cases show co-occurrence of multiple brain pathologies that overlap with other NDDs of aging, such as cerebral small vessel disease, and Lewy body dementia. Minimum to above-threshold levels of Alzheimer's disease pathology are also observed in a considerable proportion (39\%) of dementia patients not clinically diagnosed as probable Alzheimer's disease (Beach et al., 2012). Alzheimer's disease pathology has also been demonstrated in postmortem studies of CN older adults (Bennett et al., 2006), and it remains 
medRxiv preprint doi: https://doi.org/10.1101/19008615; this version posted October 10, 2019. The copyright holder for this preprint (which was not certified by peer review) is the author/funder, who has granted medRxiv a license to display the preprint in perpetuity. Author Submitted Versismade available under a CC-BY-NC-ND 4.0 International license . Badhwar et al.

unclear if such individuals would have developed Alzheimer's disease symptoms with time, should they have lived longer (Jagust, 2013). Overall, "top-down" clinical labels, based primarily on cognitive symptoms, imperfectly align with biomarkers of neurodegeneration. Additional biomarkers are thus urgently needed to characterize the clinico-pathological heterogeneity of Alzheimer's disease, and to disambiguate it from other age-related NDDs and normal aging (Jack et al., 2018).

A radically different paradigm to NDDs is to move away from "top-down" clinical labels, and concentrate on pathological signatures built "bottom up", using unsupervised machine learning algorithms and high-throughput 'omics' metrics that screen global facets of an organism. These data-driven approaches provide new opportunities to probe the complex etiology of Alzheimer's disease from multiple levels (example network, cellular, and molecular), and to identify biomarker signatures with high diagnostic/prognostic value. This review focuses on the following omics approaches: brain connectomics, metabolomics, and genomics. These omics data capture complementary information on Alzheimer's disease emergence and progression: brain connectomics (and morphometry) can track accrued neurodegeneration and other sources of network impairments, metabolomics provides a global small-molecule snapshot that is sensitive to ongoing pathological processes, and genomics characterizes relatively invariant genetic risk factors representing key pathways associated with Alzheimer's disease (Jack et al., 2018). The high-dimensional nature of omics "big data" can prove challenging to process, manipulate, and visualize, even when a single modality is involved. Multiple redundancies are often present in these measures, and not all data points provide independent information as they tend to covary due to shared biological processes. We focus this review on three omics data reduction techniques that capture disease-relevant population heterogeneity with a limited number of indicators: neuroimaging-based subtypes, metabolite panels, and polygenic risk score or PRS. Neuroimaging subtypes are based on data-driven algorithms that identify patient subgroups with homogeneous brain imaging features. Metabolite panels are developed via data-driven algorithms applied to thousands of small molecules representing global biochemical events and distinguishing clinical phenotypes. PRS and other empirically derived representations of interactive or multi-gene risk may represent key domains of mechanisms and pathways to Alzheimer's disease. Following this focused review, we discuss the rationale and challenges for assembling multiomics diagnostic tools highly predictive of individual clinical trajectories, and in particular, the importance of pathophysiological heterogeneity in research clinical cohorts. 
medRxiv preprint doi: https://doi.org/10.1101/19008615; this version posted October 10, 2019. The copyright holder for this preprint (which was not certified by peer review) is the author/funder, who has granted medRxiv a license to display the preprint in perpetuity. Author Submitted Versis'made available under a CC-BY-NC-ND 4.0 International license. Badhwar et al.

\section{Materials and Methods}

We conducted parallel focused reviews of PubMed articles published between January 2011 to June 2018 in three omics domains: brain connectomics (and morphometry), metabolomics, and genomics. We included studies investigating Alzheimer's disease in human and published in English. Additional articles (that met criteria) were identified by scanning the reference lists of selected PubMed articles. Described in the following three sections are search characteristics specific to each omics domain. We have provided in Supplementary Material (Supplementary Tables S1, S2, and S5) characteristics of the 40 domain-specific omics studies included.

\section{Brain morphology and connectomics}

Search term combinations used for brain morphology and connectomics in neuroimaging are provided in were: (1) alzheimer's disease OR alzheimer pathology AND subtype, (2) mild cognitive impairment OR amnestic mild cognitive impairment OR MCI OR amnestic MCI AND hierarchical clustering; resting-state AND functional MRI AND alzheimer AND clustering, (3) alzheimer's disease OR alzheimer pathology AND structural subtype, (4) alzheimer's disease OR alzheimer pathology AND structural MRI AND clustering, (5) restingstate AND functional MRI AND alzheimer AND hierarchical clustering, (6) diffusion MRI AND alzheimer AND clustering, (7) diffusion MRI AND alzheimer AND hierarchical clustering; diffusion MRI AND hierarchical clustering. To these we applied the "common" exclusion criteria. Thereafter, only studies reporting AD spectrum subgroups identified using data-driven methods were included. It should be noted that neuroimaging-based subtyping is an emergent field and there is still a lack of consistent terminology. Therefore, to avoid missing relevant studies due to stringent use of terminology, search combinations 1 and 2, used relaxed and inclusive keywords, which captured all of the morphometry based literature. In total, 12 papers met our criteria, and were reviewed.

\section{Metabolomics}

Search term combinations for metabolomics were: (1) alzheimer's disease AND metabolomics panels; (2) alzheimer's disease AND metabolomics profiles; (3) alzheimer's disease AND metabolomics networks; (4) alzheimer's disease AND metabolomics pathways; (5) alzheimer's disease AND metabolomics biomarkers. To these we applied the common exclusion criteria. We further excluded: reviews and technical reports; articles not relevant to AD metabolomic panels, pathways, or networks; and studies using a targeted metabolomics 
medRxiv preprint doi: https://doi.org/10.1101/19008615; this version posted October 10, 2019. The copyright holder for this preprint (which was not certified by peer review) is the author/funder, who has granted medRxiv a license to display the preprint in perpetuity. Author Submitted Versismade available under a CC-BY-NC-ND 4.0 International license. Badhwar et al.

approach. Five papers were identified from reference list scans. In total, 11 studies were reviewed. Details on key metabolites highted in the 11 studies were compiled from three different databases: Kyoto Encyclopedia of Genes and Genomes (KEGG, https://www.genome.jp/kegg/pathway.html) Pathway Database, Human Metabolome Database (HMDB, http://www.hmdb.ca/) and PubMed. These details were used to generate Fig. $2 \mathrm{~b}$ and are provided in Supplementary Table S3.

\section{Genomics}

Search term combinations used for the genomics were: (Polygenic Risk Scale OR Polygenic Risk Index OR Genetic Risk Score OR Genetic Risk Scale OR Genetic Risk Index) AND (Alzheimer Disease OR Alzheimers Disease OR Alzheimer's Disease), which identified 264 potential papers. To these we applied the "common" exclusion criteria, followed by exclusion of single-gene studies. In total 17 studies were reviewed. References used for the compilation of the genes in Supplementary Table S4 are provided in the Supplemental Reference section. 


\section{Brain Subtypes}
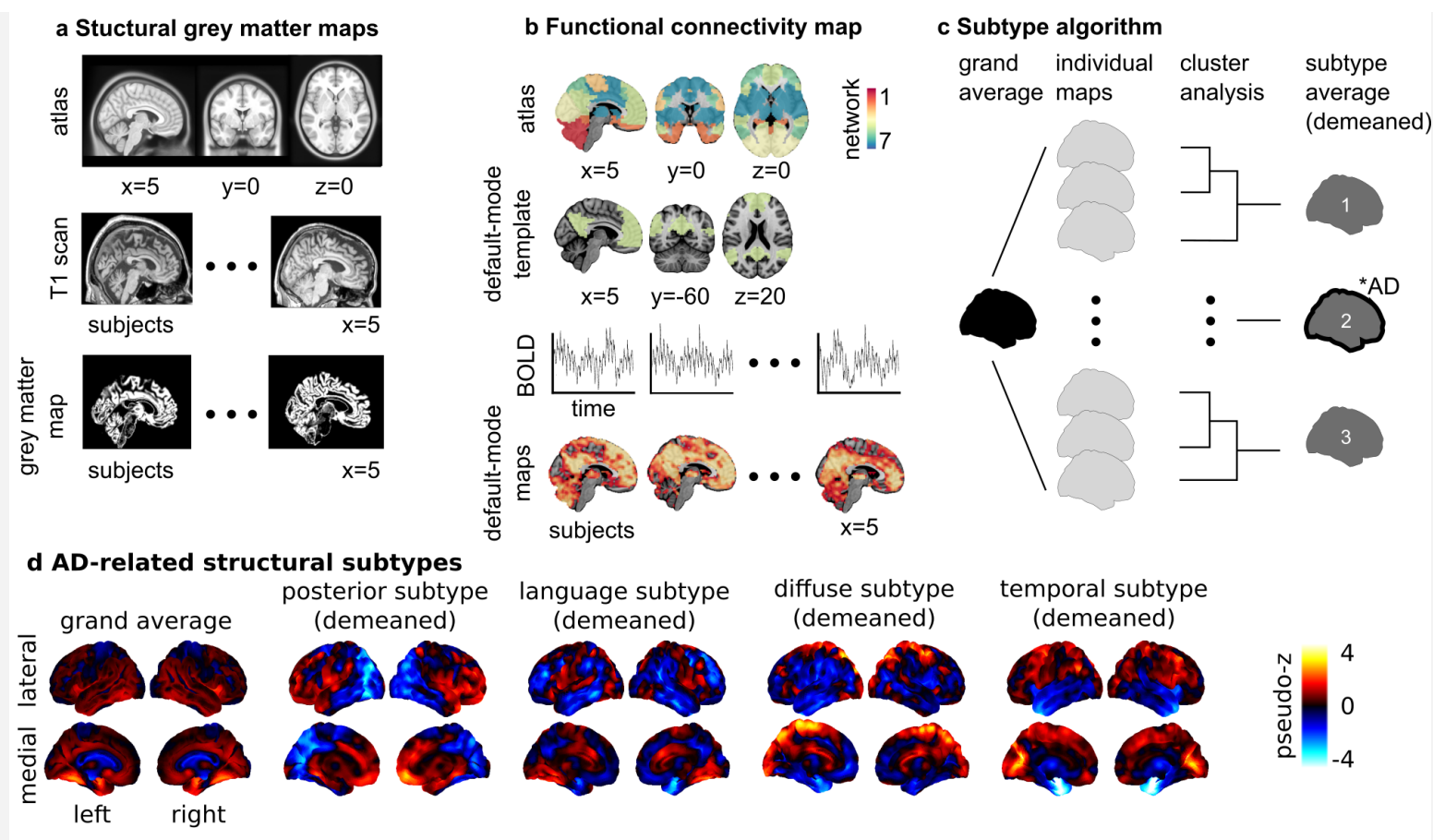

temporal subtype
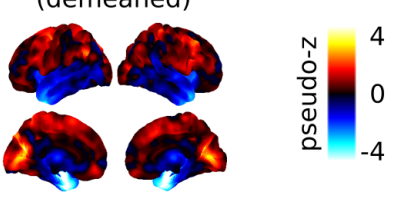

e AD-related functional subtypes default mode network

salience network subtype average subtype average

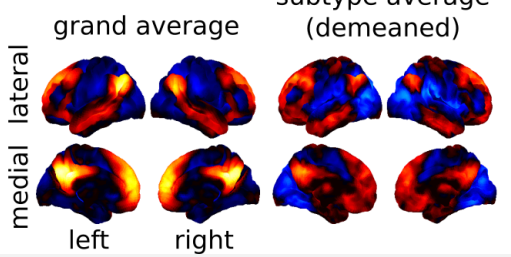
(demeaned)

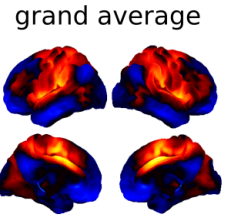

limbic network subtype average grand average (demeaned)

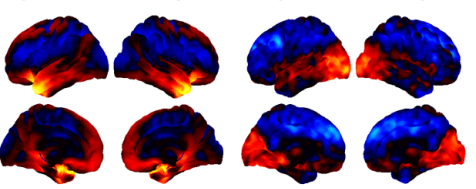

Figure 1: Brain morphology and connectomics Alzheimer's disease-related subtypes

Neuroimaging provides insight into the effect of neurodegeneration on brain health. There exist different tools that can capture distinct, yet complementary, aspects of brain structure and function. The most established neuroimaging marker of neurodegeneration is grey matter atrophy, measured by structural MRI. Structural MRI is a non-invasive technique widely used in both research and clinical practice. To generate structural maps, individual structural MRI scans are first spatially aligned to a reference template or atlas (1a). Then for each individual and each voxel (smallest volume element in MRI data), a metric characterizing the local structure of the grey matter is generated (1a), such as grey matter volume, cortical thickness or surface area. Using these approaches, it is possible to monitor the thinning of grey matter, which likely reflects the death of neuronal cell bodies at advanced stages of neurodegeneration. Synaptic disruption is an early event in Alzheimer's disease (Sperling et al., 2011), and functional networks may have the ability to compensate the impact of neurodegeneration on 
medRxiv preprint doi: https://doi.org/10.1101/19008615; this version posted October 10, 2019. The copyright holder for this preprint (which was not certified by peer review) is the author/funder, who has granted medRxiv a license to display the preprint in perpetuity. Author Submitted Versismade available under a CC-BY-NC-ND 4.0 International license . Badhwar et al.

cognitive symptoms (Franzmeier et al., 2017). For these reasons, intrinsic functional connectivity from resting-state fMRI is an emerging Alzheimer's disease biomarker that holds promise for early diagnosis (Sperling et al., 2011; Badhwar et al., 2017). To analyze restingstate fMRI, select regions in canonical brain networks previously established in the literature are generally considered (1b). An individual resting-state fMRI connectivity map can be generated for different networks, with the default-mode, limbic, and salience networks being the key components affected by Alzheimer's disease (Badhwar et al., 2017) (1b). Structural and functional brain maps enter a subtyping procedure, which identifies groups of individuals with homogeneous brain maps (1c). The number of subtypes are defined a priori or through various metrics for model selection (Seghier, 2018) (for example $\mathrm{N}=3$ in 1c). A subtype map is generated by averaging the maps within each subgroup and subtracting the grand average (i.e. demeaned) to emphasize the features of the subtype. Chi square statistics are applied to identify groups that include a greater number of Alzheimer's disease patients than expected by chance (illustrated by a "*AD” annotation for subtype 2 in $1 \mathrm{c}$ ). In $1 \mathrm{~d}$, the subtyping procedure was applied on maps of grey matter density from $\mathrm{CN}$ and Alzheimer's disease dementia individuals in the ADNI database $(\mathrm{N}=377)$. Four out of seven subtypes were identified as Alzheimer's disease dementia-related (results adapted from Tam and colleagues (Tam et al., 2018)). Three subtypes were consistent with previous reports: posterior (or temporo-occipitoparietal-predominant), diffuse, and temporal (or medial temporal-predominant) atrophy subtypes. A novel language atrophy subtype was also identified. In 1e, the subtype procedure was applied to resting-state fMRI data collected on $\mathrm{CN}$, MCI, and Alzheimer's disease dementia individuals in a dataset pooling ADNI2 with several independent samples $(\mathrm{N}=130)$. Three subtypes were extracted for three resting-state networks known to be impacted by Alzheimer's disease: default-mode, salience, and limbic. One Alzheimer's disease dementia/MCI-related subtype was found for each network. The salience and default-mode followed similar patterns: increased within-network connectivity, and a lower (negative) connectivity between networks. The limbic subtypes showed lower connectivity with frontal regions, and increased connectivity with occipital regions. Results adapted from Orban et al. (Orban et al., 2017). The section on "Brain Subtypes" compares results from the abovementioned and other studies with similar approaches and objectives. Supplementary Table S1 provides detailed characteristics of the 12 neuroimaging subtyping studies (structural MRI and resting-state $\mathrm{fMRI}$ ) that met our search criteria. Abbreviations: BOLD (blood oxygen level dependant sigal) 
medRxiv preprint doi: https://doi.org/10.1101/19008615; this version posted October 10, 2019. The copyright holder for this preprint (which was not certified by peer review) is the author/funder, who has granted medRxiv a license to display the preprint in perpetuity. Author Submitted Versismade available under a CC-BY-NC-ND 4.0 International license . Badhwar et al.

\section{Anatomical subtypes}

The spatial distribution of brain atrophy on structural MRI is highly heterogeneous in MCI, and Alzheimer's disease dementia patients (Nettiksimmons et al., 2014; Poulakis et al., 2018). Using data-driven clustering algorithms, 11 studies have attempted to subtype and characterize this inherent heterogeneity (Supplementary Table S1). Seven studies reported at least three distinct atrophy subtypes in Alzheimer's disease dementia (Noh et al., 2014; Hwang et al., 2016; Park et al., 2017; Poulakis et al., 2018; ten Kate et al., 2018), or mixed (Alzheimer's disease dementia and CN) cohorts (Varol et al., 2017; Tam et al., 2018). Subtypes were generally consistent across studies, and can be described as diffuse, medial temporalpredominant (temporal), and temporo-occipito-parietal-predominant (posterior) (Fig. 1d). They were generated by applying (1) hierarchical agglomerative clustering using Ward's clustering linkage (Noh et al., 2014; Hwang et al., 2016; Tam et al., 2018), Louvain clustering (Park et al., 2017), random forest clustering (Poulakis et al., 2018), or non-negative matrix factorization (ten Kate et al., 2018) on cortical thickness or grey matter density maps, or (2) clustering on grey matter density maps using a novel approach called HYDRA (Varol et al., 2017). Good agreement across studies may, in part, reflect usage of the same data sample (ADNI) for subtype identification in four studies (Hwang et al., 2016; Varol et al., 2017; Poulakis et al., 2018; Tam et al., 2018). Some studies report two-subtype decomposition (Dong et al., 2016; Malpas, 2016), but these lack inter-study consensus. Using model-based clustering on regional cortical thickness measures from ADNI, Malpas reported normal and atrophicentorhinal subtypes in a sample including Alzheimer's disease dementia, and CN individuals (Malpas, 2016). The atrophic-entorhinal subtype demonstrated considerable heterogeneity in entorhinal thickness, suggesting the presence of additional subtypes (Malpas, 2016). Dong et al. reported limbic-insular, and parietal-occipital atrophy subtypes using CHIMERA clustering on brain volume data from Alzheimer's disease dementia and CN ADNI participants (Dong et al., 2016). In a separate study, the same group reported four atrophy subtypes using CHIMERA: normal, temporal, and two diffuse subtypes - one with predominant temporal involvement (diffuse-temporal), and one without (diffuse) (Dong et al., 2017). Visually, the diffuse subtype from CHIMERA shared some overlap with the posterior subtype described previously. In general, the reported subtypes (Dong et al., 2017) fit better with the three subtype solution, considering that, unlike previous studies, the CHIMERA study included CN individuals. Finally, Tam et al. identified a fourth atrophy subtype involving several languagerelated areas (Tam et al., 2018). 
medRxiv preprint doi: https://doi.org/10.1101/19008615; this version posted October 10, 2019. The copyright holder for this preprint (which was not certified by peer review) is the author/funder, who has granted medRxiv a license to display the preprint in perpetuity. Author Submitted Versismade available under a CC-BY-NC-ND 4.0 International license. Badhwar et al.

The choice of the number of subtypes is to some degree arbitrary. Two studies showed that their three subtypes could be decomposed into six (Noh et al., 2014), or more (Tam et al., 2018) homogeneous groups. Finally, an additional study looking at heterogeneity with a linear mixture model, instead of a discrete cluster analysis, showed that most individuals tend to express varying levels of multiple subtypes (Zhang et al., 2016). Continuous measures of subtype similarity are thus more advisable than discrete assignment (Zhang et al., 2016; Tam et al., 2018).

We now highlight various associations between Alzheimer's disease markers/risk-factors and the three atrophy subtypes consistently reported. In three studies, Alzheimer's disease dementia patients with the posterior subtype were reported to be the youngest, and had the earliest ageat-onset (Noh et al., 2014; Hwang et al., 2016; Park et al., 2017). They also demonstrated greater PET-detectable amyloidosis (Hwang et al., 2016), and pathological levels of CSF A $\beta 42$ and tau (Noh et al., 2014; Varol et al., 2017; ten Kate et al., 2018). Differences across subtypes were reported with FDG-PET-detectable glucose hypometabolism (Hwang et al., 2016), and white matter hyperintensities (ten Kate et al., 2018). Subtype-specific associations with Alzheimer's disease-related genes were observed, specifically, APOE (Noh et al., 2014; Varol et al., 2017), CD2AP (CD2-associated protein) (Varol et al., 2017), SPON1 (Spondin-1) (Varol et al., 2017), LOC390956 or PPIAP59 (peptidyl-prolyl cis-trans isomerase A pseudogene) (Varol et al., 2017), though the association with $A P O E$ was not consistently found (Hwang et al., 2016). Associations of subtypes with cognition were observed for global (Varol et al., 2017; Tam et al., 2018) and domain-specific (e.g. episodic memory) (Noh et al., 2014; Park et al., 2017; Poulakis et al., 2018; ten Kate et al., 2018) measures, but not by all studies (Hwang et al., 2016). Associations between subtypes and sex were found to be significant in two (Noh et al., 2014; Varol et al., 2017) of four (Noh et al., 2014; Hwang et al., 2016; Varol et al., 2017; Tam et al., 2018) studies.

\section{Functional subtypes}

By coupling cluster analysis and resting-state functional MRI, a preprint report by Orban et al. (Orban et al., 2017) investigated connectivity subtypes in CN, MCI, and Alzheimer's disease dementia patients (Supplementary Table S1). They noted associations between functional connectivity subtypes and cognitive symptoms in the default-mode, limbic, and salience 
medRxiv preprint doi: https://doi.org/10.1101/19008615; this version posted October 10, 2019. The copyright holder for this preprint (which was not certified by peer review) is the author/funder, who has granted medRxiv a license to display the preprint in perpetuity. Author Submitted Versismade available under a CC-BY-NC-ND 4.0 International license. Badhwar et al.

networks in MCI, and Alzheimer's disease dementia patients (Fig. 1e). Limbic subtypes were also associated with Alzheimer's disease biomarkers (CSF Aß42 levels, APOE4 genotype) in an independent cohort at increased risk for familial Alzheimer's disease, suggesting that functional connectivity subtypes may be sensitive to the presence and progression of preclinical disease (Orban et al., 2017).

\section{Summary}

Our review found convergent evidence of distinct brain atrophy subtypes in Alzheimer's disease dementia patients, including at least three data-driven Alzheimer's disease atrophy subtypes: diffuse, temporal, and posterior. These structural subtypes seem to associate with established biomarkers, risk factors, and clinical symptoms of Alzheimer's disease, as well as cognitive subtypes: temporal subtype with memory impairment, and diffuse subtype with impaired executive function (Zhang et al., 2016). The picture emerging from fMRI data is one of aberrant between-network connectivity initiating in the mesolimbic network at the preclinical stage and propagating to the salience and default-mode network with Alzheimer's disease progression (Orban et al., 2017). 


\section{Metabolomics Panels}
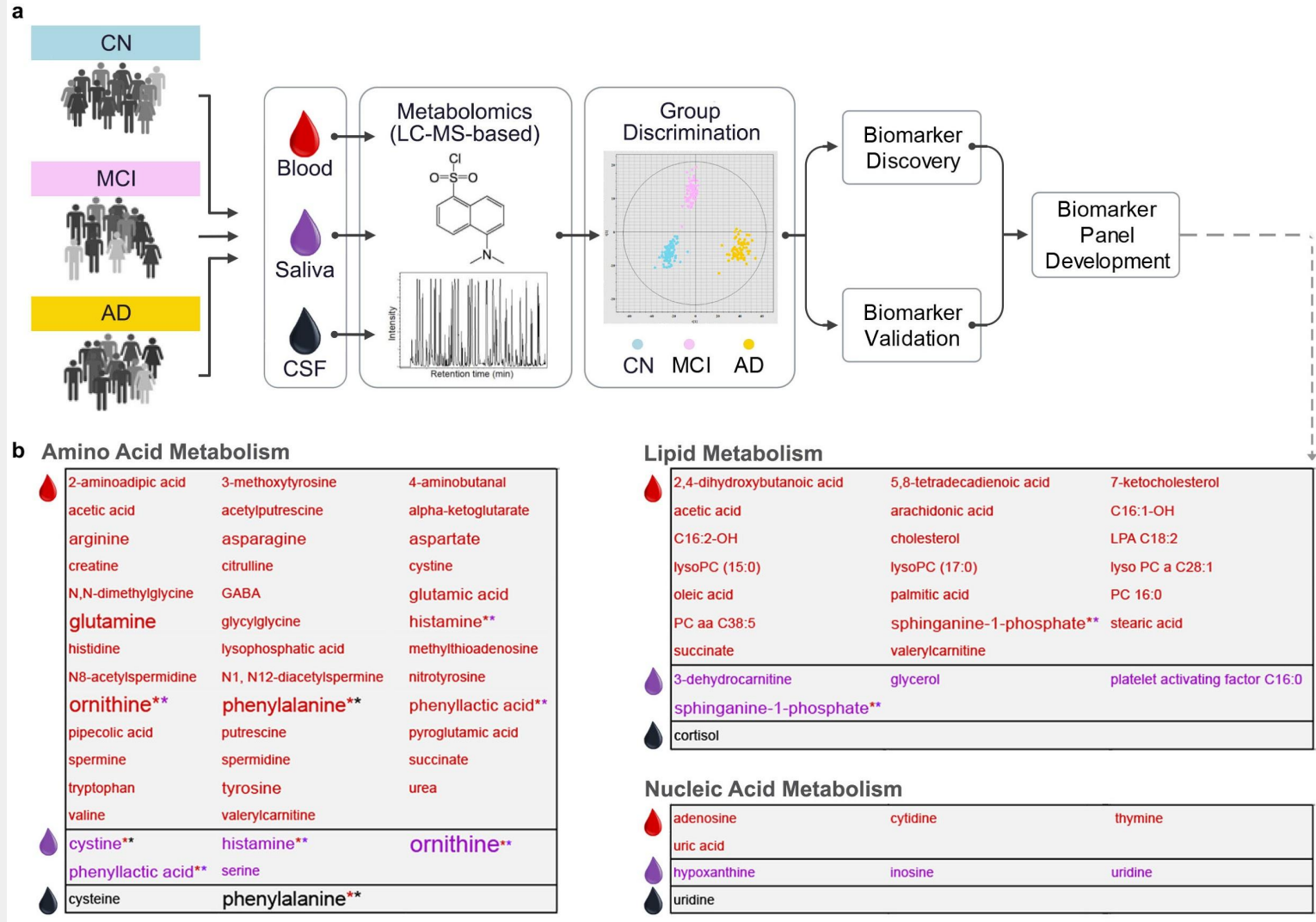

\section{Figure 2: A typical Alzheimer's disease metabolomics biomarker discover pipeline}

Metabolomics is a relatively recent addition to the systems biology toolkit for the study of NDDs of aging (Wilkins and Trushina, 2017). It encompasses the global study of smallmolecules (50-1500 daltons in mass), that are substrates and products of metabolism. Together, these metabolites (e.g. amino acids, antioxidants, vitamins) represent the overall physiological status of the organism. An individual's metabolic activity is influenced by an individual's genotype and environment (Kaddurah-Daouk et al., 2011). Analysis of the metabolome, therefore, provides an opportunity to study the dynamic molecular phenotype of an individual. Untargeted metabolomics approaches are increasingly used to compare two or more groups (e.g. Alzheimer's disease dementia and $\mathrm{CN}$ participants) and identify metabolite profiles associated with a disease. These profiles provide insight into underlying disease mechanisms, as well as constitute candidates for biomarker discovery and drug development. In the field of Alzheimer's disease research, metabolomics studies (targeted and untargeted) over the last decade have examined several biofluids and tissues, including serum, plasma, CSF, saliva, urine, and brain tissue (Wilkins and Trushina, 2017). Technologies include NMR (nuclear magnetic resonance) spectroscopy and mass spectrometry. In 2a, a typical Alzheimer's disease 
medRxiv preprint doi: https://doi.org/10.1101/19008615; this version posted October 10, 2019. The copyright holder for this preprint (which was not certified by peer review) is the author/funder, who has granted medRxiv a license to display the preprint in perpetuity. Author Submitted Versismade available under a CC-BY-NC-ND 4.0 International license . Badhwar et al.

metabolomics biomarker discovery pipeline using MS-LC (mass spectrometry-liquid chromatography) is depicted. Subsequent to metabolite extraction, identification, and quantification, most studies apply multivariate statistical methods to the metabolome data to identify the top discriminant metabolites. These can be further combined into metabolite-panels to increase discriminative power (i.e. sensitivity and specificity) in Alzheimer's disease prediction and progression (Liang et al., 2015, 2016; Huan et al., 2018). Significant discriminative power is commonly tested with the Receiver Operating Characteristic curve analysis (area under the curve or AUC values). Discriminant metabolite-panels are then validated in independent samples. Following discriminant metabolite(s) discovery, researchers conduct pathway and network analyses, which provide crucial mechanistic insights into the sequences of processes leading to the heterogeneous phenotypes of neurodegeneration. Pathway analysis focus on identifying sequences of processes that lead to the presence of a discriminant metabolite. Network analysis examine how discriminant metabolites are connected to each other within Alzheimer's disease and related dementias. In 2b, we show the three main metabolic pathways (namely, amino acid, lipid and nucleic acid) that 90 Alzheimer's disease-associated metabolites in our review ( $N=11$ publications, Supplementary Table S2) were found to belong. The text color indicates the biofluid metabolome each metabolite was identified in: red $=$ serum or plasma, purple $=$ saliva, black $=$ CSF . A larger font size indicates that the metabolite was identified in more than one study (see Supplementary Table S3 for details) The maximum number of studies a metabolite was detected in our review was four. * indicates that the metabolite was identified in more than one biofluid:** indicates presence in plasma or serum and saliva, $* *$ indicates presence in plasma or serum and CSF. Abbreviations: AD, Alzheimer's disease; CN, cognitively normal; MCI, mild cognitive impairment.

\section{Metabolite Panels}

We reviewed six Alzheimer's disease studies that constructed metabolite panels from top discriminant metabolites in biofluids: 2 plasma, 1 serum, 2 saliva, and 1 CSF (Supplementary Table S2). Using plasma metabolome data, Wang et al. (Wang et al., 2014) constructed a sixmetabolite panel to discriminate Alzheimer's disease dementia from $\mathrm{CN}$, and a five-metabolite panel to discriminate amnestic MCI from CN. Arachidonic acid, N,N-dimethylglycine, and thymine were present in both panels. Association of panel metabolites with lipid, amino acid, or nucleic acid metabolism suggested specific metabolic deregulations in Alzheimer's disease. Mapstone et al. (Mapstone et al., 2017) used a 12-plasma-metabolite panel to discriminate the 
medRxiv preprint doi: https://doi.org/10.1101/19008615; this version posted October 10, 2019. The copyright holder for this preprint (which was not certified by peer review) is the author/funder, who has granted medRxiv a license to display the preprint in perpetuity. Author Submitted Versismade available under a CC-BY-NC-ND 4.0 International license . Badhwar et al.

following cohorts from $\mathrm{CN}$ : older adults with superior memory; amnestic MCI + Alzheimer's disease dementia patients; and participants who converted to amnestic MCI or Alzheimer's disease dementia in approximately two years. Similar to Wang et al. (Wang et al., 2014), several panel metabolites were associated with lipid or amino acid metabolism. Panel metabolites were also found to be constituents of pathways regulating oxidative stress, inflammation, and nitric oxide bioavailability. Using serum metabolome data, Liang et al. (Liang et al., 2016) identified a panel of two lipid metabolites (spinganine-1-phosphate, 7ketocholesterol) that discriminated MCI from Alzheimer's disease dementia. Sphinganine-1phosphate was also present in a three-metabolite panel constructed from the salivary metabolome, and discriminated Alzheimer's disease dementia patients from CN (Liang et al., 2015). The other two panel members, ornithine and phenyllactic acid, were amino acid metabolites (Ogata et al., 1999) with links to the same oxidative stress pathway reported by Mapstone et al. (Mapstone et al., 2017) A separate study using saliva reported a sevenmetabolite panel that discriminated pre-dementia (i.e. five years prior to dementia onset) from CN (Figueira et al., 2016). Metabolites were associated with amino acid, lipid, or energy metabolism. Czech et al. (Czech et al., 2012) assessed multiple combinations of 16 CSF metabolites to discriminate Alzheimer's disease dementia from CN. Highest discrimination was obtained with a 5-metabolite panel consisting of cortisol and amino acids. Our focused review of Alzheimer's disease-associated metabolite panels highlight that the majority of discriminant molecules detected in biofluids are involved in amino acid, lipid, or nucleic acid metabolism (Fig. 2b).

\section{Metabolomics Pathways and Networks}

We reviewed five Alzheimer's disease studies that followed up non-targeted metabolomics research in biofluids with pathway or network analyses: 2 plasma, 1 plasma plus CSF, and 2 serum (Supplementary Table S2). In plasma, de Leeuw et al. (de Leeuw et al., 2017) identified 26 metabolites comprised of mainly amino acids and lipids with significantly altered levels in Alzheimer's disease dementia patients. Network analyses suggested a shift in Alzheimer's disease towards amine and oxidative stress compounds, known to cause imbalances in neurotransmitter production, $A \beta$ generation, and neurovascular health. Perturbations in amino acid metabolism (interlinked polyamine and L-arginine pathways) was also demonstrated in the plasma metabolome of MCI to Alzheimer's disease dementia converters (Graham et al., 2015). Changes in polyamine and L-arginine metabolism have been linked to neurotoxicity, and deregulations in genesis and/or death of neural cells and neurotransmitter production 
medRxiv preprint doi: https://doi.org/10.1101/19008615; this version posted October 10, 2019. The copyright holder for this preprint (which was not certified by peer review) is the author/funder, who has granted medRxiv a license to display the preprint in perpetuity. Author Submitted Versismade available under a CC-BY-NC-ND 4.0 International license. Badhwar et al.

(Graham et al., 2015). Other metabolic pathways notably impacted were cholesterol, glucose, and prostaglandin (Graham et al., 2015). Cholesterol metabolism (specifically cholesterol and sphingolipids transport) was also found to be abnormal in both plasma and CSF from Alzheimer's disease dementia patients (Trushina et al., 2013). In serum, metabolism of amino acids dominated the top pathways altered in Alzheimer's disease dementia patients in one study (González-Domínguez et al., 2015), a finding in line with plasma metabolome data (de Leeuw et al., 2017). A second study in serum reported a 3-metabolite panel predictive of progression from MCI to Alzheimer's disease dementia (within 27 \pm 18 months), with major contribution from up-regulated 2,4-dihydroxybutanoic acid, a metabolite potentially overproduced during hypoperfusion-related hypoxia (Orešič et al., 2011). Upregulation of the pentose phosphate pathway in progressors further supported the involvement of secondary hypoxia in Alzheimer's disease pathogenesis. More glucose is metabolized via the pentose phosphate pathway in the brain under hypoxic conditions.

\section{Summary}

Overall, metabolite panels, and metabolomics pathway and network analyses provide the following insights: (1) discriminant Alzheimer's disease-associated metabolites may be narrowly or broadly interconnected (Wilkins and Trushina, 2017); (2) metabolomes of different biofluids provide convergent and biofluid-related mechanistic insights into Alzheimer's disease pathology (Trushina et al., 2013); (3) genotype-associated (e.g. APOE status) differences in preclinical and clinical groups suggest different routes to Alzheimer's disease (de Leeuw et al., 2017), (4) neurodegenerative disease subtypes can be characterized by metabolomics analyses (de Leeuw et al., 2017). 


\section{Genomics-derived Polygenic Risk Scores}
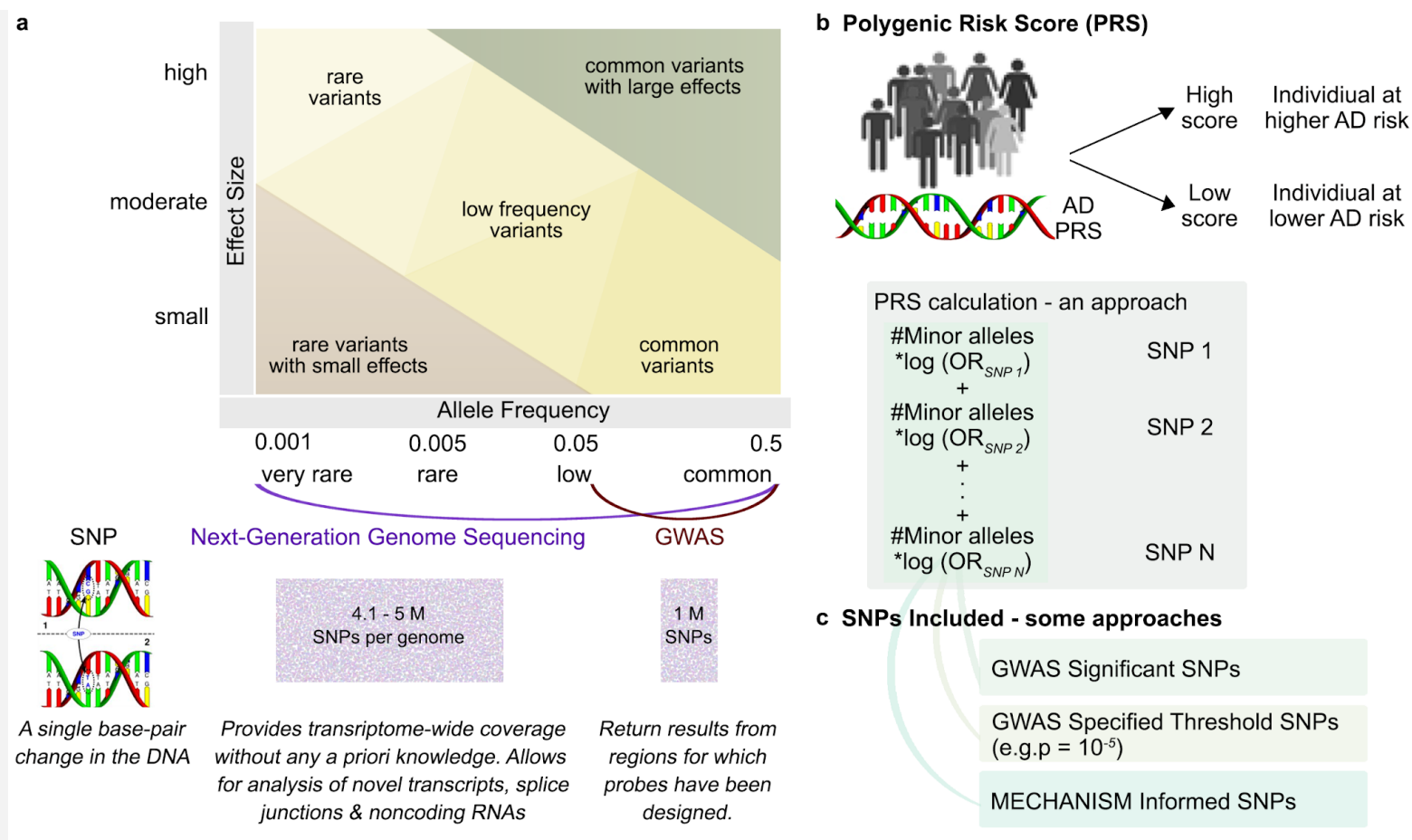

\section{d Major Mechanistic Pathways Underlying AD}
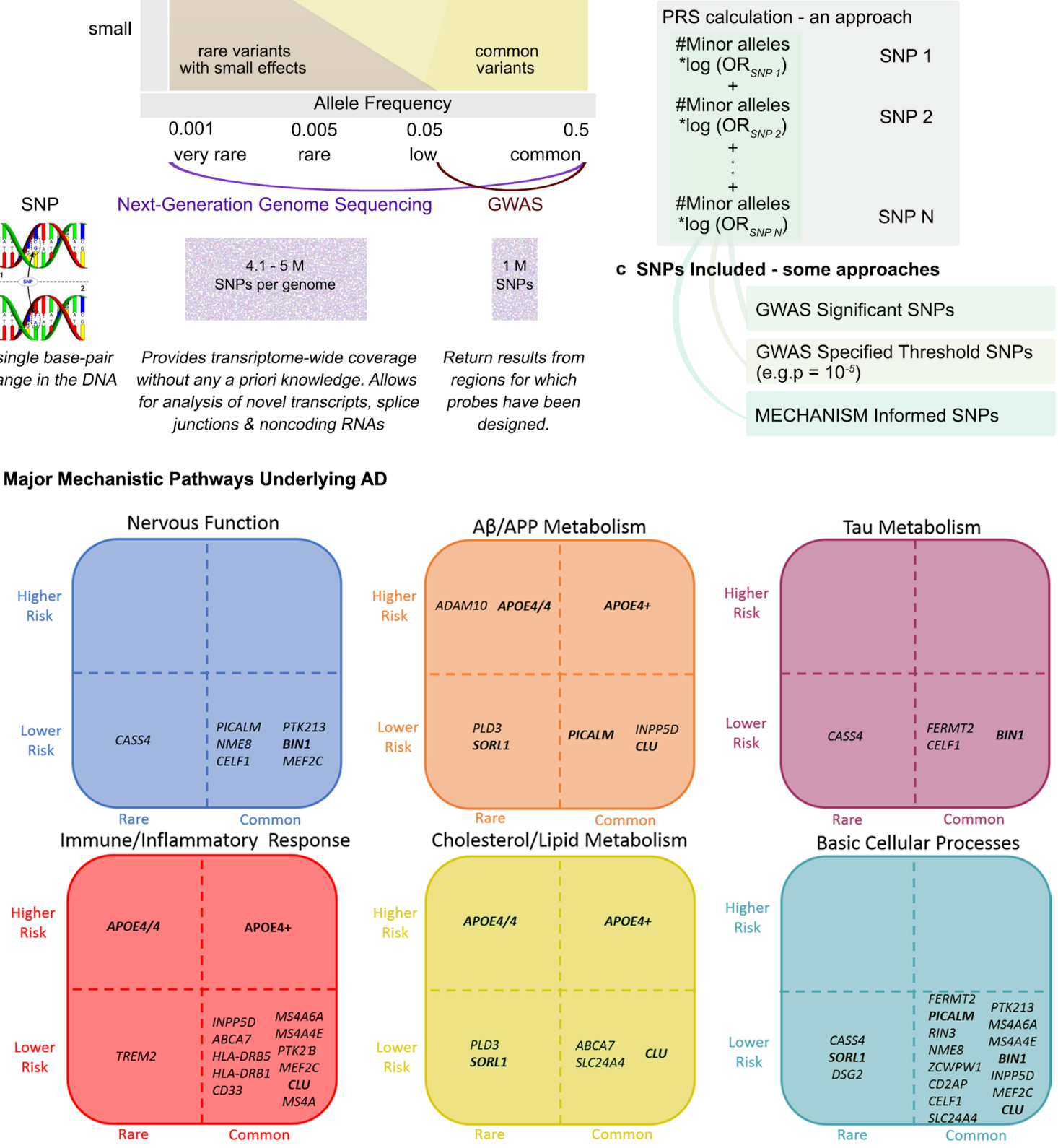

c SNPs Included - some approaches

GWAS Significant SNPS
GWAS Specified Threshold SNPs
$\left(\right.$ e.g.p $\left.=10^{-5}\right)$
MECHANISM Informed SNPS

\section{Figure 3: Polygenic Risk Scores}

High-throughput genotyping technologies have revolutionized studies in diseases with complex genetics by enabling detection of common genetic variants with low effect sizes, and rarer variants with relatively higher effect sizes (see 3a). In Alzheimer's disease, the prevalent late-onset variant is genetically complex and demonstrates high heritability (up to 80\%) (Gatz 
medRxiv preprint doi: https://doi.org/10.1101/19008615; this version posted October 10, 2019. The copyright holder for this preprint (which was not certified by peer review) is the author/funder, who has granted medRxiv a license to display the preprint in perpetuity. Author Submitted Versismade available under a CC-BY-NC-ND 4.0 International license. Badhwar et al.

et al., 2006), whereas the early-onset familial variant is deterministically driven by single gene mutation(s) in PSEN1 (presenilin 1), PSEN2 (presenilin 2) or the APP (amyloid precursor protein) (Guerreiro et al., 2013). The genetics of late-onset Alzheimer's disease has been predominantly investigated using GWAS. Designed to rapidly scan for statistical links between a set of known SNPs and a phenotype of interest, GWAS can identify common variants with MAF greater than 5\% (Torkamani et al., 2018) (see 3a). Up to 24 key Alzheimer's disease-risk genes have been identified using GWAS (Supplementary Table S4). Identification of rarer Alzheimer's disease-associated SNPs (MAF $>0.5 \%$ and $<5 \%$ ), that often escape detection with GWAS, is being enabled by NGS technologies, such as whole-exome sequencing and targeted resequencing of disease-associated genes (Bras et al., 2012; Masellis et al., 2013) (see Supplementary Table S4 for examples). NGS technologies provide transcriptome-wide coverage without requiring any a priori knowledge of SNPs (3a). To date, Alzheimer's disease prediction using individual high-throughput genotyping technologies identified risk genes have been predominantly non-significant, with the exception of $A P O E$, which accounts for up to $30 \%$ of the genetic risk (Daw et al., 2000). Therefore, the search for risk genes beyond APOE now include polygenic risk score (PRS, also referred to as genetic risk scores, risk indexes or scales) approaches (3b). A PRS is a calculation (e.g. weighted sum) based on the number of risk alleles carried by an individual, where the risk alleles and their weights are defined by GWAS-detected loci and their measured effects (Torkamani et al., 2018). In the most common scenario, only SNPs reaching conventional GWAS significance $\left(p<5 \times 10^{-8}\right)$ are included (3c). A threshold lower than the genome-wide statistical significance (e.g. $p=10^{-5}$ ) can also be used to improve or estimate total predictability (Torkamani et al., 2018) (3c). SNPs representing multiple hits among Alzheimer's disease risk genes from one or more major mechanistic pathways can also be included into a PRS (3c). Displayed are six main mechanistic clusters, each populated by genetic variants thought to represent the cluster (3d). Genetic variants have been placed within the cluster according to population frequency (horizontal axis) and level of estimated risk (vertical axis). For example, an A $\beta / A P P$ metabolism cluster is made up of rare ADAM10 (a disintegrin and metalloproteinase domain-containing protein 10) and common APOE4+)higher risk genes, and rare PLD3 (phospholipase D family member 3) and common PICALM (phosphatidylinositol binding clathrin assembly protein) lower risk genes. Some genes are involved with multiple mechanisms as can be seen for PICALM's involvement in nervous function, basic cellular processes, and A $\beta / A P P$ metabolism. As implied in the figure, when creating PRS, it may be very useful to select genes within mechanistic groups, and select 
medRxiv preprint doi: https://doi.org/10.1101/19008615; this version posted October 10, 2019. The copyright holder for this preprint (which was not certified by peer review) is the author/funder, who has granted medRxiv a license to display the preprint in perpetuity. Author Submitted Versismade available under a CC-BY-NC-ND 4.0 International license . Badhwar et al.

groups depending on the purpose of the research. In sum, PRS reflect a large number of SNPs and a complex set of biological mechanisms related to Alzheimer's disease pathogenesis, and can improve the precision of early Alzheimer's disease risk or diagnosis (Desikan et al., 2017; Escott-Price et al., 2017; Morgan et al., 2017).

\section{Polygenic Risk Score Approach or PRS}

Constructed of multiple SNPs that implicate one or more biological mechanisms, PRS (Fig. 3) are better at discriminating Alzheimer's disease from $\mathrm{CN}$ than single-gene analysis (EscottPrice et al., 2017; Torkamani et al., 2018). We reviewed 11 Alzheimer's disease PRS studies (Supplementary Table S4, S5), the majority comprised of GWAS-detected SNPs. To identify genetic risk beyond that of $A P O E$ alone, several studies assessed PRS with (APOE-PRS) and without (non-APOE-PRS) APOE. Desikan et al. (Desikan et al., 2017) found that an APOEPRS associated with age-at-onset of Alzheimer's disease symptoms, decreased A $\beta$ and increased tau in CSF, and increased atrophy, tau, and A $\beta$ load in brain. APOE-PRS also associated with plasma inflammatory markers in Alzheimer's disease patients (Morgan et al., 2017). An APOE-PRS including a rare TREM2 (triggering receptor expressed on myeloid cells 2) variant discriminated Alzheimer's disease dementia and $\mathrm{CN}$, with increasing scores associating with decreasing age-at-onset, and CSF A $\beta 42$ (Sleegers et al., 2015). Discriminative power of $A P O E$-PRS was found to improve with diagnostic accuracy, as demonstrated using a pathologically confirmed Alzheimer's disease cohort (Escott-Price V, Myers, AJ, Huentelman $\mathrm{M}$, Hardy, J, 2017). In four separate studies, a non-APOE-PRS was reported to discriminate between Alzheimer's disease dementia and CN (Xiao et al., 2015), as well as associate with MCI (Adams et al., 2015), increased risk of Alzheimer's disease dementia (Adams et al., 2015; Chouraki et al., 2016; Tosto et al., 2017), and earlier Alzheimer's disease onset (Tosto et al., 2017). Inclusion of $A P O E$ either resulted in a modest increase in discriminative power (Xiao et al., 2015), stronger clinical or biomarker associations (Adams et al., 2015; Chouraki et al., 2016), or had no additional effect (Tosto et al., 2017). In another non-APOE-PRS study in Alzheimer's disease patients, PRS scores correlated negatively with CSF A $\beta 42$ levels, and positively with temporal cortex A $\beta$ pathology, and $\gamma$-secretase activity (Martiskainen et al., 2015). Naj et al. (Naj et al., 2014) found that though APOE contributed to 3.7\% of age-at-onset variability in Alzheimer's disease dementia patients, adding a non-APOE-PRS accounted for an additional 2.2\%. Overall, Alzheimer's disease heritability has a large polygenic contribution 
medRxiv preprint doi: https://doi.org/10.1101/19008615; this version posted October 10, 2019. The copyright holder for this preprint (which was not certified by peer review) is the author/funder, who has granted medRxiv a license to display the preprint in perpetuity. Author Submitted Versis'made available under a CC-BY-NC-ND 4.0 International license. Badhwar et al.

beyond $A P O E$, which makes PRS approaches pivotal for Alzheimer's disease-risk prediction (Escott-Price et al., 2015).

\section{Mechanism-based Interaction and Network Approaches}

Alzheimer's disease-risk genes can be clustered into functional/mechanistic pathways (Fig. 3d), and the information gained utilised to improve Alzheimer's disease discrimination and/or risk prediction (Gaiteri et al., 2016; Hu et al., 2017). We reviewed six mechanism-based Alzheimer's disease studies (Supplementary Table S5). Functional variants of Alzheimer's disease GWAS-significant SNPs (e.g. CELF1 or CUGBP Elav-like family member 1) was reported to associate with human brain expression quantitative trait loci, and preferentially expressed in specific cell-types (e.g. microglia) (Karch et al., 2016). Rosenthal et al. (Rosenthal et al., 2014) highlighted the potential regulatory functions of non-coding Alzheimer's disease GWAS SNPs. Protein-protein interaction network analyses highlighted that Alzheimer's disease-risk genes whose protein-products interact physically may be under positive evolutionary selection (e.g. PICALM or phosphatidylinositol binding clathrin assembly protein, BIN1 or bridging integrator 1, CD2AP or CD2 associated protein, EPHA1 or EPH receptor A1) (Raj et al., 2012). Ebbert et al. (Ebbert et al., 2014) reported that while an APOEPRS did not improve discrimination of Alzheimer's disease from $\mathrm{CN}$ over $A P O E$, a model allowing for epistatic interactions between SNPs increased discriminative power. Patel et al. (Patel et al., 2016) applied a stratified false discovery rate approach, used to increase GWAS power by adjusting significance levels to the amount of overall signal present in data, to identify gene networks and provide links with sMRI phenotypes: e.g. linking genes involved in transport (e.g. SLC4A10 or solute carrier family 4 member 10, KCNH7 or potassium voltagegated channel subfamily H member 7) with hippocampal volume. Huang et al. (Huang et al., 2018) integrated Alzheimer's disease GWAS genes with human brain-specific gene network using machine learning to identify additional Alzheimer's disease-risk genes.

\section{Summary}

In sum, PRSs may contribute substantially to accounting for the genetic variability that distinguishes Alzheimer's disease from MCI and CN groups. They may also be used to probe genetic underpinnings of Alzheimer's disease subtypes as well as related and disparate NDDs. Thus far, research reporting PRSs in relation to conversion rates of CN or MCI to Alzheimer's disease dementia have been mixed (Adams et al., 2015; Lacour et al., 2017), but early PRS 
medRxiv preprint doi: https://doi.org/10.1101/19008615; this version posted October 10, 2019. The copyright holder for this preprint (which was not certified by peer review) is the author/funder, who has granted medRxiv a license to display the preprint in perpetuity. Author Submitted Versis'made available under a CC-BY-NC-ND 4.0 International license. Badhwar et al.

prediction of cognitive trajectories and clinical outcomes have also been reported (Sapkota and Dixon, 2018).

\section{Discussion}

\section{Roadmap for assembling multiomics measures into diagnostic tool}

\section{On the complementarity of multiomics biomarkers}

Individuals clinically diagnosed with an NDD of aging (e.g. Alzheimer's disease) exhibit varying loads of neurodegenerative markers (e.g. A $\beta$, tau, alpha-synuclein, brain atrophy, vascular abnormalities) (Beach et al., 2012; Robinson et al., 2018). Single-domain omics biomarkers can, to an extent, characterize this heterogeneity in vivo. Some data-driven brain atrophy subtypes parallel established clinical diagnoses. For example, the posterior atrophy subtype is evocative of the PCA Alzheimer's disease variant, and the language atrophy subtype of the lvPPA variant (Ossenkoppele et al., 2015). An active area of research is to determine to what degree the "bottom-up", fully automated and data-driven subtypes match with established "top-down" clinical assessments, which usually start with cognitive symptoms and then incorporate specific neuroimaging characteristics, such as left temporoparietal atrophy in lvPPA (Ossenkoppele et al., 2015). The fact that reviewed studies included participants with typical late-onset Alzheimer's disease dementia, and not atypical variants such as PCA, suggest that specific brain atrophy phenotypes comprise a spectrum of involvement that may overlap a clinical label, but not associate uniquely with one. It is unclear how functional connectivity subtypes tie in with atrophy subtypes, although they both associate with clinical diagnoses and biomarkers and risk factors of Alzheimer's disease (Zhang et al., 2016; Orban et al., 2017). Although the propagation of functional dysconnectivity parallels the Braak staging of Alzheimer's disease, the mix of connectivity increases and decreases observed in patients may reflect transient compensatory mechanisms as well as neurodegeneration (Badhwar et al., 2017). To date, we are unaware of studies that have associated data-driven Alzheimer's disease brain subtypes with PRS and/or metabolite panels, but our review strongly supports such coordinated multiomics approaches. For example, an Alzheimer's disease PRS comprised of genes linked to lipid metabolism and inflammatory response may associate with panels comprised of metabolites involved in corresponding pathways. One could further speculate whether the resulting inflammation may cause the diffuse atrophy subtype, and trigger specific 
medRxiv preprint doi: https://doi.org/10.1101/19008615; this version posted October 10, 2019. The copyright holder for this preprint (which was not certified by peer review) is the author/funder, who has granted medRxiv a license to display the preprint in perpetuity. Author Submitted Versismade available under a CC-BY-NC-ND 4.0 International license. Badhwar et al.

functional compensatory mechanisms. Testing these hypotheses will require a cohort that is both deeply phenotyped and captures the entire spectrum of age-related dementia.

\section{A roadmap for parsing heterogeneity in neurodegeneration}

A data-driven characterization of heterogeneity across the NDDs of aging will require cohorts representative of the spectrum of neurodegeneration. The cohort assembled by the Canadian Consortium on Neurodegeneration in Aging (CCNA, http://ccna-ccnv.ca/) provides a new opportunity to study the full spectrum of age-related dementia. By 2019, the cohort will include 2,310 individuals (ages 50-90) featuring the following cognitive conditions: Alzheimer's disease, vascular, Lewy Body, Parkinson's, frontotemporal, and mixed etiology dementias, as well as subjective cognitive impairment, MCI, vascular MCI, and CN (Fig. 4). 
medRxiv preprint doi: https://doi.org/10.1101/19008615; this version posted October 10, 2019. The copyright holder for this preprint (which was not certified by peer review) is the author/funder, who has granted medRxiv a license to display the preprint in perpetuity. Author Submitted Verstismade available under a CC-BY-NC-ND 4.0 International license. Badhwar et al.

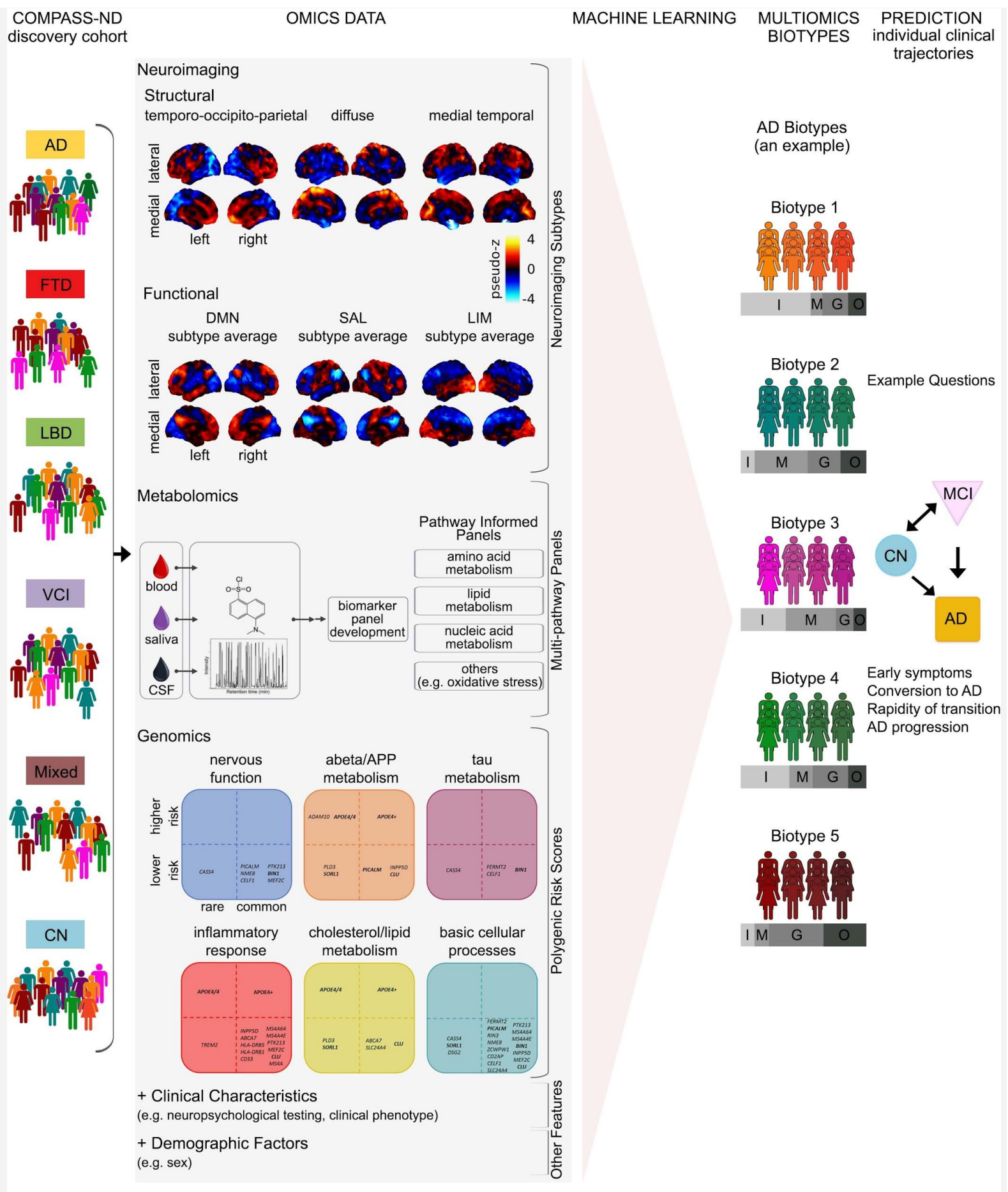

Figure 4: proposed roadmap to discovering multiomics Alzheimer's disease biomarkers

Panel 1 (COMPASS-ND): The COMPASS-ND cohort is comprised of people with various types of dementia or cognitive complaints, as well as healthy, cognitively normal individuals. Panel 2 (Omics data): Performing dimension reduction for omics data. Featured as examples are some of the results of our review of the Alzheimer's disease literature as presented earlier in the paper. Panels 3-5 (Machine Learning, Multiomics Biotypes and Prediction): demonstrate how signatures of neurodegeneration derived from the integration of multiomics data using 
medRxiv preprint doi: https://doi.org/10.1101/19008615; this version posted October 10, 2019. The copyright holder for this preprint (which was not certified by peer review) is the author/funder, who has granted medRxiv a license to display the preprint in perpetuity. Author Submitted Versismade available under a CC-BY-NC-ND 4.0 International license . Badhwar et al.

machine learning techniques will better identify individuals on an Alzheimer's disease spectrum trajectory. While our proposed roadmap addresses multiomics biomarkers for Alzheimer's disease, a similar approach can be used for other neurodegenerative diseases of aging. Abbreviations: Alzheimer's Disease (AD), FrontoTemporal Dementia (FTD), Lewy Body Disease (LBD), Vascular Cognitive Impairment (VCI), Mixed etiology dementia (Mixed), Cognitively normal (CN), Subjective Cognitive Impairment (SCI), Mild Cognitive Impairment (MCI), Imaging features (I), Metabolic features (M), Genomics features (G), clinical and demographic features $(\mathrm{O})$.

The cohort composition ensures that age-related dementias are more or less equally represented, even for less prevalent dementia types (e.g. frontotemporal dementia). Participants will be deeply phenotyped with extensive clinical, neuropsychological, neuroimaging, biospecimen, and neuropathological assessments.

In Fig. 4 we present a roadmap for a multiomics approach to heterogeneity in NDD. We begin with a heterogeneous clinical cohort design that enables the discovery of subgroups sharing a common signature across multiple omics domains (biotypes) that are highly predictive of the clinical status and evolution of individual patients. Multiomics biotypes will be complemented by other important variables such as sex, presence of $\mathrm{A} \beta$ and tau deposits, and vascular abnormalities. Machine learning tools will be applied to identify an optimal combination of different biotypes and explanatory variables that either discriminate different clinical cohorts, or are predictive of future progression of specific symptoms (Fig. 4).

\section{Towards highly predictive multiomics signatures}

Biomarkers of Alzheimer's disease dementia demonstrate limited predictive power in the prodromal phase (Rathore et al., 2017). For example, Korolev et al. (Korolev et al., 2016) reached about $80 \%$ accuracy (specificity $76 \%$, sensitivity $83 \%$ ) by including cognitive, multimodal imaging, and plasma-proteomics measures in a predictive model of progression. The best models include a combination of cognitive, sMRI, FDG-PET, and/or amyloid-PET measures (Rathore et al., 2017). A substantial proportion of patients identified as progressors, even by the best model, will remain stable over time. Given a $30 \%$ baseline rate of progressors in an MCI cohort, and a prediction achieving a sensitivity and specificity of $80 \%, 37 \%$ of patients identified as progressors by the model will remain stable. This limited positive predictive value is likely explained by sample heterogeneity. For example, Dong et al. (Dong 
medRxiv preprint doi: https://doi.org/10.1101/19008615; this version posted October 10, 2019. The copyright holder for this preprint (which was not certified by peer review) is the author/funder, who has granted medRxiv a license to display the preprint in perpetuity. Author Submitted Versismade available under a CC-BY-NC-ND 4.0 International license. Badhwar et al.

et al., 2017) reported two atrophy subtypes with higher-than-expected rates of progression to dementia, but one subtype was much more at risk than the other. Thus, an important first step to precision medicine is to identify specific subsets of patients where an accurate prediction can be made.

Multiomics signatures can be used to improve the accuracy of early prognosis, but they also capture a range of information, ranging from brain networks targeted by the disease, metabolic abnormalities in specific pathways, and distinct genetic backgrounds. The multiomics signature thus may also help elucidate the specific pathophysiological pathways involved. Overall, multiomics biomarkers have the potential to reshape clinical diagnosis, and define new "bottom up" cohorts based on markers of underlying pathologies to design and evaluate drugs.

\section{Author Contributions}

$\mathrm{AB}, \mathrm{PB}, \mathrm{RAD}, \mathrm{GPM}$, and SS designed and wrote the manuscript. AB, GPM and SS performed literature search and compiled tables. AB, PB, RAD, GPM and SS made the figures and MM provided input. MM, LL, SD, HC, and SEB helped with the writing and interpretation of specific sections of the manuscript.

\section{Acknowledgements}

We would like to thank Dr. Sridar Narayanan for helpful comments on the manuscript.

\section{Funding}

This review was performed by members of the Biomarkers Team of the Canadian Consortium on Neurodegeneration in Aging (CCNA; Team Leads: RAD and PB) which is funded by the Canadian Institutes of Health Research (CIHR) and partners. Additional sources of support are as follows. AB is currently supported by a CIHR Postdoctoral Fellowship (funding reference number \#152548) and the Courtois Foundation. At the start of the project AB was supported by the Alzheimer Society of Canada Postdoctoral Fellowship. PB is a Research Scholar from the Fonds de recherche du Québec, and is also supported by the Courtois Foundation. SS is supported by the Alzheimer Society of Canada Postdoctoral Fellowship. RAD and GPM are also supported by the U.S. National Institutes of Health (National Institute on Aging, R01 AG008235). SD is a Research Scholar from the Fonds de recherche du Québec - Santé [grant number 30801]. The Consortium d'identification précoce de la maladie d'Alzheimer - Québec 
medRxiv preprint doi: https://doi.org/10.1101/19008615; this version posted October 10,2019 . The copyright holder for this preprint (which
was not certified by peer review) is the author/funder, who has granted medRxiv a license to display the preprint in perpetuity. Author Submitted Versismade available under a CC-BY-NC-ND 4.0 International license. Badhwar et al.

is financed through the Fonds de recherche du Québec - Santé / Pfizer Canada Innovation Fund [grant number 25262].

\section{Competing Interests}

The authors report no conflict of interest with regards to submitted manuscript.

\section{Supplementary Material}

We have provided 5 tables in supplementary material: Supplementary Tables S1, S2, S3, S4, and S5. 
medRxiv preprint doi: https://doi.org/10.1101/19008615; this version posted October 10, 2019. The copyright holder for this preprint (which was not certified by peer review) is the author/funder, who has granted medRxiv a license to display the preprint in perpetuity. Author Submitted Versis'made available under a CC-BY-NC-ND 4.0 International license. Badhwar et al.

\section{References}

Adams HHH, de Bruijn RFAG, Hofman A, Uitterlinden AG, van Duijn CM, Vernooij MW, et al. Genetic risk of neurodegenerative diseases is associated with mild cognitive impairment and conversion to dementia. Alzheimers Dement 2015; 11: 1277-1285.

Anstey KJ, Eramudugolla R, Hosking DE, Lautenschlager NT, Dixon RA. Bridging the Translation Gap: From Dementia Risk Assessment to Advice on Risk Reduction. J Prev Alzheimers Dis 2015; 2: 189-198.

Badhwar A, Tam A, Dansereau C, Orban P, Hoffstaedter F, Bellec P. Resting-state network dysfunction in Alzheimer's disease: A systematic review and meta-analysis. Alzheimers Dement 2017; 8: 73-85.

Beach TG, Monsell SE, Phillips LE, Kukull W. Accuracy of the clinical diagnosis of Alzheimer disease at National Institute on Aging Alzheimer Disease Centers, 2005-2010. J Neuropathol Exp Neurol 2012; 71: 266-273.

Bennett DA, Schneider JA, Arvanitakis Z, Kelly JF, Aggarwal NT, Shah RC, et al. Neuropathology of older persons without cognitive impairment from two community-based studies. Neurology 2006; 66: 1837-1844.

Bras J, Guerreiro R, Hardy J. Use of next-generation sequencing and other whole-genome strategies to dissect neurological disease. Nat Rev Neurosci 2012; 13: 453-464.

Chouraki V, Reitz C, Maury F, Bis JC, Bellenguez C, Yu L, et al. Evaluation of a Genetic Risk Score to Improve Risk Prediction for Alzheimer's Disease. J Alzheimers Dis 2016; 53: 921-932.

Czech C, Berndt P, Busch K, Schmitz O, Wiemer J, Most V, et al. Metabolite profiling of Alzheimer's disease cerebrospinal fluid. PLoS One 2012; 7: e31501.

Daw EW, Payami H, Nemens EJ, Nochlin D, Bird TD, Schellenberg GD, et al. The number of trait loci in late-onset Alzheimer disease. Am J Hum Genet 2000; 66: 196-204.

Desikan RS, Fan CC, Wang Y, Schork AJ, Cabral HJ, Cupples LA, et al. Genetic assessment of age-associated Alzheimer disease risk: Development and validation of a polygenic hazard score. PLoS Med 2017; 14: e1002258.

Dong A, Honnorat N, Gaonkar B, Davatzikos C. CHIMERA: Clustering of Heterogeneous Disease Effects via Distribution Matching of Imaging Patterns. IEEE Trans Med Imaging 2016; 35: 612-621.

Dong A, Toledo JB, Honnorat N, Doshi J, Varol E, Sotiras A, et al. Heterogeneity of neuroanatomical patterns in prodromal Alzheimer's disease: links to cognition, progression and biomarkers. Brain 2017; 140: 735-747.

Dumurgier J, Hanseeuw BJ, Hatling FB, Judge KA, Schultz AP, Chhatwal JP, et al. Alzheimer's Disease Biomarkers and Future Decline in Cognitive Normal Older Adults [Internet]. J Alzheimers Dis 2017Available from: http://dx.doi.org/10.3233/JAD-170511 
medRxiv preprint doi: https://doi.org/10.1101/19008615; this version posted October 10, 2019. The copyright holder for this preprint (which was not certified by peer review) is the author/funder, who has granted medRxiv a license to display the preprint in perpetuity. Author Submitted Versis'made available under a CC-BY-NC-ND 4.0 International license. Badhwar et al.

Ebbert MTW, Ridge PG, Wilson AR, Sharp AR, Bailey M, Norton MC, et al. Populationbased analysis of Alzheimer's disease risk alleles implicates genetic interactions. Biol Psychiatry 2014; 75: 732-737.

Escott-Price V, Myers, AJ, Huentelman M, Hardy, J. Polygenic Risk Score Analysis of Pathologically Confirmed Alzheimer Disease. Ann Neurol 2017; 82: 311-314.

Escott-Price V, Shoai M, Pither R, Williams J, Hardy J. Polygenic score prediction captures nearly all common genetic risk for Alzheimer's disease. Neurobiol Aging 2017; 49: 214.e7214.e11.

Escott-Price V, Sims R, Bannister C, Harold D, Vronskaya M, Majounie E, et al. Common polygenic variation enhances risk prediction for Alzheimer's disease. Brain 2015; 138: 36733684.

Figueira J, Jonsson P, Nordin Adolfsson A, Adolfsson R, Nyberg L, Öhman A. NMR analysis of the human saliva metabolome distinguishes dementia patients from matched controls. Mol Biosyst 2016; 12: 2562-2571.

Franzmeier N, Duering M, Weiner M, Dichgans M, Ewers M, Alzheimer's Disease Neuroimaging Initiative (ADNI). Left frontal cortex connectivity underlies cognitive reserve in prodromal Alzheimer disease. Neurology 2017; 88: 1054-1061.

Gaiteri C, Mostafavi S, Honey CJ, De Jager PL, Bennett DA. Genetic variants in Alzheimer disease - molecular and brain network approaches. Nat Rev Neurol 2016; 12: 413-427.

Gatz M, Reynolds CA, Fratiglioni L, Johansson B, Mortimer JA, Berg S, et al. Role of genes and environments for explaining Alzheimer disease. Arch Gen Psychiatry 2006; 63: 168-174.

González-Domínguez R, García-Barrera T, Gómez-Ariza JL. Metabolite profiling for the identification of altered metabolic pathways in Alzheimer's disease. J Pharm Biomed Anal 2015; 107: 75-81.

Graham SF, Chevallier OP, Elliott CT, Hölscher C, Johnston J, McGuinness B, et al. Untargeted metabolomic analysis of human plasma indicates differentially affected polyamine and L-arginine metabolism in mild cognitive impairment subjects converting to Alzheimer's disease. PLoS One 2015; 10: e0119452.

Guerreiro R, Brás J, Hardy J. SnapShot: Genetics of Alzheimer's Disease. Cell 2013; 155: 968-968.e1.

Huang X, Liu H, Li X, Guan L, Li J, Tellier LCAM, et al. Revealing Alzheimer's disease genes spectrum in the whole-genome by machine learning. BMC Neurol 2018; 18: 5.

Huan T, Tran T, Zheng J, Sapkota S, MacDonald SW, Camicioli R, et al. Metabolomics Analyses of Saliva Detect Novel Biomarkers of Alzheimer's Disease. J Alzheimers Dis 2018; 65: 1401-1416.

Hu Y-S, Xin J, Hu Y, Zhang L, Wang J. Analyzing the genes related to Alzheimer's disease via a network and pathway-based approach. Alzheimers Res Ther 2017; 9: 29.

Hwang J, Kim CM, Jeon S, Lee JM, Hong YJ, Roh JH, et al. Prediction of Alzheimer's 
medRxiv preprint doi: https://doi.org/10.1101/19008615; this version posted October 10, 2019. The copyright holder for this preprint (which was not certified by peer review) is the author/funder, who has granted medRxiv a license to display the preprint in perpetuity. Author Submitted Versis'made available under a CC-BY-NC-ND 4.0 International license. Badhwar et al.

disease pathophysiology based on cortical thickness patterns. Alzheimers Dement 2016; 2: $58-67$.

Jack CR Jr, Bennett DA, Blennow K, Carrillo MC, Dunn B, Haeberlein SB, et al. NIA-AA Research Framework: Toward a biological definition of Alzheimer's disease. Alzheimers Dement 2018; 14: 535-562.

Jack CR Jr, Bennett DA, Blennow K, Carrillo MC, Feldman HH, Frisoni GB, et al. A/T/N: An unbiased descriptive classification scheme for Alzheimer disease biomarkers. Neurology 2016; 87: 539-547.

Jack CR Jr, Bernstein MA, Fox NC, Thompson P, Alexander G, Harvey D, et al. The Alzheimer's Disease Neuroimaging Initiative (ADNI): MRI methods. J Magn Reson Imaging 2008; 27: 685-691.

Jagust W. Vulnerable neural systems and the borderland of brain aging and neurodegeneration. Neuron 2013; 77: 219-234.

Kaddurah-Daouk R, Rozen S, Matson W, Han X, Hulette CM, Burke JR, et al. Metabolomic changes in autopsy-confirmed Alzheimer's disease. Alzheimers Dement 2011; 7: 309-317.

Karch CM, Ezerskiy LA, Bertelsen S, Alzheimer's Disease Genetics Consortium (ADGC), Goate AM. Alzheimer's Disease Risk Polymorphisms Regulate Gene Expression in the ZCWPW1 and the CELF1 Loci. PLoS One 2016; 11: e0148717.

ten Kate M, Dicks E, Visser PJ, van der Flier WM, Teunissen CE, Barkhof F, et al. Atrophy subtypes in prodromal Alzheimer's disease are associated with cognitive decline [Internet]. Brain 2018[cited 2018 Nov 6] Available from: https:/academic.oup.com/brain/advancearticle-abstract/doi/10.1093/brain/awy264/5142624?redirectedFrom=fulltext

Korolev IO, Symonds LL, Bozoki AC, Alzheimer's Disease Neuroimaging Initiative. Predicting Progression from Mild Cognitive Impairment to Alzheimer's Dementia Using Clinical, MRI, and Plasma Biomarkers via Probabilistic Pattern Classification. PLoS One 2016; 11: e0138866.

Lacour A, Espinosa A, Louwersheimer E, Heilmann S, Hernández I, Wolfsgruber S, et al. Genome-wide significant risk factors for Alzheimer's disease: role in progression to dementia due to Alzheimer's disease among subjects with mild cognitive impairment. Mol Psychiatry 2017; 22: 153-160.

de Leeuw FA, Peeters CFW, Kester MI, Harms AC, Struys EA, Hankemeier T, et al. Bloodbased metabolic signatures in Alzheimer's disease. Alzheimers Dement 2017; 8: 196-207.

Liang Q, Liu H, Zhang T, Jiang Y, Xing H, Zhang A-H. Metabolomics-based screening of salivary biomarkers for early diagnosis of Alzheimer's disease. RSC Adv 2015; 5: 96074 96079.

Liang Q, Liu H, Zhang T, Jiang Y, Xing H, Zhang A-H. Discovery of serum metabolites for diagnosis of progression of mild cognitive impairment to Alzheimer's disease using an optimized metabolomics method. RSC Adv 2016; 6: 3586-3591.

Malpas CB. Structural neuroimaging correlates of cognitive status in older adults: A person- 
medRxiv preprint doi: https://doi.org/10.1101/19008615; this version posted October 10, 2019. The copyright holder for this preprint (which was not certified by peer review) is the author/funder, who has granted medRxiv a license to display the preprint in perpetuity. Author Submitted Versis'made available under a CC-BY-NC-ND 4.0 International license. Badhwar et al.

oriented approach. J Clin Neurosci 2016; 30: 77-82.

Mapstone M, Lin F, Nalls MA, Cheema AK, Singleton AB, Fiandaca MS, et al. What success can teach us about failure: the plasma metabolome of older adults with superior memory and lessons for Alzheimer's disease. Neurobiol Aging 2017; 51: 148-155.

Martiskainen H, Helisalmi S, Viswanathan J, Kurki M, Hall A, Herukka S-K, et al. Effects of Alzheimer's disease-associated risk loci on cerebrospinal fluid biomarkers and disease progression: a polygenic risk score approach. J Alzheimers Dis 2015; 43: 565-573.

Masellis M, Sherborn K, Neto PR, Sadovnick DA, Hsiung G-YR, Black SE, et al. Earlyonset dementias: diagnostic and etiological considerations. Alzheimers Res Ther 2013; 5: S7.

Morgan AR, Touchard S, O'Hagan C, Sims R, Majounie E, Escott-Price V, et al. The Correlation between Inflammatory Biomarkers and Polygenic Risk Score in Alzheimer's Disease. J Alzheimers Dis 2017; 56: 25-36.

Naj AC, Jun G, Reitz C, Kunkle BW, Perry W, Park YS, et al. Effects of multiple genetic loci on age at onset in late-onset Alzheimer disease: a genome-wide association study. JAMA Neurol 2014; 71: 1394-1404.

Nettiksimmons J, DeCarli C, Landau S, Beckett L, Alzheimer's Disease Neuroimaging Initiative. Biological heterogeneity in ADNI amnestic mild cognitive impairment. Alzheimers Dement 2014; 10: 511-521.e1.

Noh Y, Jeon S, Lee JM, Seo SW, Kim GH, Cho H, et al. Anatomical heterogeneity of Alzheimer disease: based on cortical thickness on MRIs. Neurology 2014; 83: 1936-1944.

Ogata H, Goto S, Sato K, Fujibuchi W, Bono H, Kanehisa M. KEGG: Kyoto Encyclopedia of Genes and Genomes. Nucleic Acids Res 1999; 27: 29-34.

Olanrewaju O, Clare L, Barnes L, Brayne C. A multimodal approach to dementia prevention: A report from the Cambridge Institute of Public Health. Alzheimers Dement 2015; 1: 151156.

Orban P, Tam A, Urchs S, Savard M, Madjar C, Badhwar A, et al. Subtypes of functional brain connectivity as early markers of neurodegeneration in Alzheimer's disease. bioRxiv 2017: 195164.

Orešič M, Hyötyläinen T, Herukka S-K, Sysi-Aho M, Mattila I, Seppänan-Laakso T, et al. Metabolome in progression to Alzheimer's disease. Transl Psychiatry 2011; 1: e57.

Ossenkoppele R, Cohn-Sheehy BI, La Joie R, Vogel JW, Möller C, Lehmann M, et al. Atrophy patterns in early clinical stages across distinct phenotypes of Alzheimer's disease. Hum Brain Mapp 2015; 36: 4421-4437.

Parkinson Progression Marker Initiative. The Parkinson Progression Marker Initiative (PPMI). Prog Neurobiol 2011; 95: 629-635.

Park J-Y, Na HK, Kim S, Kim H, Kim HJ, Seo SW, et al. Robust Identification of Alzheimer's Disease subtypes based on cortical atrophy patterns. Sci Rep 2017; 7: 43270. 
medRxiv preprint doi: https://doi.org/10.1101/19008615; this version posted October 10, 2019. The copyright holder for this preprint (which was not certified by peer review) is the author/funder, who has granted medRxiv a license to display the preprint in perpetuity. Author Submitted Versis'made available under a CC-BY-NC-ND 4.0 International license. Badhwar et al.

Patel S, Park MTM, Alzheimer's Disease Neuroimaging Initiative, Chakravarty MM, Knight J. Gene Prioritization for Imaging Genetics Studies Using Gene Ontology and a Stratified False Discovery Rate Approach. Front Neuroinform 2016; 10: 14.

Poulakis K, Pereira JB, Mecocci P, Vellas B, Tsolaki M, Kłoszewska I, et al. Heterogeneous patterns of brain atrophy in Alzheimer's disease. Neurobiol Aging 2018; 65: 98-108.

Raj T, Shulman JM, Keenan BT, Chibnik LB, Evans DA, Bennett DA, et al. Alzheimer disease susceptibility loci: evidence for a protein network under natural selection. Am J Hum Genet 2012; 90: 720-726.

Rathore S, Habes M, Iftikhar MA, Shacklett A, Davatzikos C. A review on neuroimagingbased classification studies and associated feature extraction methods for Alzheimer's disease and its prodromal stages [Internet]. Neuroimage 2017Available from:

http://dx.doi.org/10.1016/j.neuroimage.2017.03.057

Robinson JL, Lee EB, Xie SX, Rennert L, Suh E, Bredenberg C, et al. Neurodegenerative disease concomitant proteinopathies are prevalent, age-related and APOE4-associated. Brain 2018; 141: 2181-2193.

Rosenthal SL, Barmada MM, Wang X, Demirci FY, Kamboh MI. Connecting the dots: potential of data integration to identify regulatory SNPs in late-onset Alzheimer's disease GWAS findings. PLoS One 2014; 9: e95152.

Sapkota S, Dixon RA. A Network of Genetic Effects on Non-Demented Cognitive Aging: Alzheimer's Genetic Risk (CLU + CR1 + PICALM) Intensifies Cognitive Aging Genetic Risk (COMT + BDNF) Selectively for APOEع4 Carriers. J Alzheimers Dis 2018; 62: 887900 .

Scheltens NME, Galindo-Garre F, Pijnenburg YAL, van der Vlies AE, Smits LL, Koene T, et al. The identification of cognitive subtypes in Alzheimer's disease dementia using latent class analysis. J Neurol Neurosurg Psychiatry 2016; 87: 235-243.

Seghier ML. Clustering of fMRI data: the elusive optimal number of clusters. PeerJ 2018; 6: e5416.

Sleegers K, Bettens K, De Roeck A, Van Cauwenberghe C, Cuyvers E, Verheijen J, et al. A 22-single nucleotide polymorphism Alzheimer's disease risk score correlates with family history, onset age, and cerebrospinal fluid A $\beta 42$. Alzheimers Dement 2015; 11: 1452-1460.

Sperling RA, Aisen PS, Beckett LA, Bennett DA, Craft S, Fagan AM, et al. Toward defining the preclinical stages of Alzheimer's disease: recommendations from the National Institute on Aging-Alzheimer's Association workgroups on diagnostic guidelines for Alzheimer's disease. Alzheimers Dement 2011; 7: 280-292.

Tam A, Dansereau C, Iturria-Medina Y, Urchs S, Orban P, Breitner J, et al. A signature of cognitive deficits and brain atrophy that is highly predictive of progression to Alzheimer's dementia. bioRxiv 2018: 352344.

Torkamani A, Wineinger NE, Topol EJ. The personal and clinical utility of polygenic risk scores. Nat Rev Genet 2018; 19: 581-590. 
medRxiv preprint doi: https://doi.org/10.1101/19008615; this version posted October 10, 2019. The copyright holder for this preprint (which was not certified by peer review) is the author/funder, who has granted medRxiv a license to display the preprint in perpetuity. Author Submitted Versismade available under a CC-BY-NC-ND 4.0 International license. Badhwar et al.

Tosto G, Bird TD, Tsuang D, Bennett DA, Boeve BF, Cruchaga C, et al. Polygenic risk scores in familial Alzheimer disease. Neurology 2017; 88: 1180-1186.

Trushina E, Dutta T, Persson X-MT, Mielke MM, Petersen RC. Identification of altered metabolic pathways in plasma and CSF in mild cognitive impairment and Alzheimer's disease using metabolomics. PLoS One 2013; 8: e63644.

Varol E, Sotiras A, Davatzikos C, Alzheimer's Disease Neuroimaging Initiative. HYDRA: Revealing heterogeneity of imaging and genetic patterns through a multiple max-margin discriminative analysis framework. Neuroimage 2017; 145: 346-364.

Wang G, Zhou Y, Huang F-J, Tang H-D, Xu X-H, Liu J-J, et al. Plasma metabolite profiles of Alzheimer's disease and mild cognitive impairment. J Proteome Res 2014; 13: 2649-2658.

Wilkins JM, Trushina E. Application of Metabolomics in Alzheimer's Disease. Front Neurol 2017; 8: 719.

Xiao Q, Liu Z-J, Tao S, Sun Y-M, Jiang D, Li H-L, et al. Risk prediction for sporadic Alzheimer's disease using genetic risk score in the Han Chinese population. Oncotarget 2015; 6: 36955-36964.

Zhang X, Mormino EC, Sun N, Sperling RA, Sabuncu MR, Yeo BTT, et al. Bayesian model reveals latent atrophy factors with dissociable cognitive trajectories in Alzheimer's disease. Proc Natl Acad Sci U S A 2016; 113: E6535-E6544. 